\title{
The condition of the hairline of Chinchilla lanigera after the introduction of a hydrogen antioxidant into the diet
}

\author{
Elena Panina, Alexey Ivanov and Dmitry Petrov* \\ Russian State Agrarian University - Moscow Timiryazev Agricultural Academy, Department of \\ Physiology, Ethology and Biochemistry of Animals, 127550 Moscow, Timiryazevskaya street, 49, \\ Russian Federaton
}

\begin{abstract}
It was found that the inclusion of water enriched with molecular hydrogen into the diet of a long-tailed chinchilla changed the fur quality indicators. In animals of the experimental group, the guard and downy hairs were thinner than in the control group. The length of downy hair in the experimental group was higher, the number of hairs in the follicle in the chinchillas of the experimental group was greater than in the control group, besides, the hair was stronger and softer. The animals of the experimental group showed less tendency to gnaw out fur. When considering the data on the chemical composition, it was found that in the dry matter of the hair of the animals of the experimental group, there were less organic substances, and there were more minerals in comparison with the animals of the control group.
\end{abstract}

\section{Introduction}

To obtain fur products in modern fur farming, various types of animals are used, both carnivorous (minks, black-brown foxes) and herbivores (nutria, rabbits). Since the 19th century, a long-tailed chinchilla (Chinchilla lanigera), a rodent that lives in South America, has been bred as a source of valuable fur on the market in Europe and North America. Due to intensive hunting, animals almost completely disappeared in the wild, and their small colonies have survived only in Chilean reserves [1]. All over the world, chinchillas are raised on farms for fur, kept as laboratory and domestic animals [2-6]. In January 2015, Chinchilla lanigera in the Russian Federation was entered into the State Register of Breeding Achievements Permitted for Use in Fur Farming [7, 8].

A feature of chinchilla fur is poor hair differentiation. Except for the guides, which make up less than $1 \%$ of the total amount of hair [9]. The hair of chinchillas is more characterized by downy and outer hairs. Guard and guide hairs, they are also called coverts, form the upper tiers that cover the layer of intermediate and downy hairs, thereby protecting the hairline $[10,11]$. Downy hairs differ little in shape, length and thickness from each other. The main criterion for distinguishing different categories of hair is the number of rows of core cells in the main part of the hair shaft. In the guide hairs in the main part of the

\footnotetext{
* Corresponding author: petrov1983dmitriy@gmail.com
} 
shaft, the core consists of 3 rows of cells; in the guard hair, it consists of 2 rows. Downy hair has a single-row pith in the main part of the hair shaft (Fig. 1). The core is more than half the thickness of the hair shaft, which reduces the thermal conductivity of the chinchilla fur and is an adaptation to the harsh climatic conditions of the natural habitats of animals. In terms of density, the chinchilla fur surpasses the fur of most fur animals. On $1 \mathrm{~cm} 2$ of the sacral part of the body there are up to 25,000 hairs, on the abdomen - about 14,000 . The height of the hair cover in Chinchilla lanigera reaches 33-34 mm. To determine the value of chinchilla fur, the density, height and evenness of the cover, the thickness and softness of the hairs are important. A dense, fully high-quality cover in the younger generation grows by $8-12$ months, during the period when immature fur is replaced by an adult one [12]. The softness of the fur coat, also called delicacy (tenderness), depends on the thickness, density and height of the hairs [13].

The quality of raw fur (raw skins) largely depends on the conditions of keeping, feeding, the introduction of various additives into the diet and the biological characteristics of animals [19]. To increase productivity and maintain the health of animals, antioxidants, natural inhibitors of free radical oxidation, are increasingly introduced into feed [20-24]. Molecular hydrogen also belongs to such means [25-28].

Molecular hydrogen is an antioxidant with favorable physicochemical properties for the body, it is electrically neutral and has a lower molecular weight in comparison with oxygen $[29,30]$. Molecular hydrogen can easily penetrate into cell membranes, nucleus, and mitochondria [31]. In addition, molecular hydrogen does not have a negative effect on physiological processes occurring both inside the cell and on the parameters of the body as a whole (temperature, blood pressure, $\mathrm{pH}$ ) [32].

Molecular hydrogen $\left(\mathrm{H}_{2}\right)$ is an efficient and non-toxic molecule with the potential to neutralize reactive oxygen species [33-36]. The biological properties of H2 were first studied in 1970 [37]. In 1975, M. Dole in Science published an article that hyperbaric hydrogen therapy reduced the size of tumors in nude mice [38]. Numerous experiments have shown that molecular hydrogen has an effect in the treatment of neurological diseases, including brain damage, Alzheimer's disease, Parkinson's disease, and so on [39-42]. Studies by K. Nagata confirmed that an abundant intake of molecular hydrogen-rich water (HRW) reduced oxidative stress in the brain and prevented stress induced in mice caused by physical isolation of animals [43]. Ethological observations have shown that the inclusion of HRW in the diet of Chinchilla lanigera increases the proportion of active behavior in the daily balance by an average of $24 \%$ [44]. Molecular hydrogen can be introduced in various ways: by inhalation of $\mathrm{H} 2$; with water enriched in molecular hydrogen; taking molecular hydrogen baths; using eye drops with molecular hydrogen [4549]. The enrichment of the body with $\mathrm{H}_{2}$ increases the concentration of the hydrogen antioxidant in the blood [50]. Sometimes HRW intake can be more effective than inhalation of $\mathrm{H} 2$, although the concentration of molecular hydrogen in water is less than inhalation [51-53]. Saturation of water with molecular hydrogen reaches its peak concentration in 5-15 minutes and returns to baseline values after 45-90 minutes after ingestion [54]. Excess molecular hydrogen is harmless because it is rapidly excreted from the body through the lungs [55].

Taking into account the numerous advantages of molecular hydrogen, it should be noted that it is also a radio protective agent [56-59]. The effect of HRW on the fur productivity of Chinchilla lanigera is not described in the literature, therefore, the purpose of our work was to study the effect of HRW on the quantitative and qualitative characteristics of the hairline to assess the quality of the fur of the long-tailed chinchilla. 


\section{Materials and methods}

For the study, ten pairs of clinically healthy male and female Chinchilla lanigera two months of age with an average weight of 268 grams were selected. The animals were housed in pairs in separate cages at a constant temperature $\left(19 \pm 2^{\circ} \mathrm{C}\right)$ with 12-hour day / night cycles and free access to food and water. Feeding was carried out ad libitum granulated feed for chinchillas.

Wooden blocks were placed in each cage for grinding the incisors. Watering of both groups of animals was carried out with an automatic watering system with the only difference that an apparatus for generating HRW "Lourdes HS-81" was connected to the automatic watering system of the experimental group. The concentration of molecular hydrogen at the outlet of the nipple drinkers of the experimental group was 0.1-1.1 ppm, depending on the operating mode of the apparatus. The apparatus for generating $\mathrm{H}_{2}$ was turned on twice a day $\left(\mathrm{H}_{2}\right.$ generation mode) in the morning and in the evening for 30 minutes, until the timer turned off, the rest of the time it worked in standby mode.

The quality of the chinchilla fur was assessed according to the following criteria: the length and diameter of the guides, guard and downy hairs and the number of hairs in the follicle. Hair samples were taken from the sacrum area. Microscope slides and a millimetre ruler were used to determine the length of the various hair categories in the extended state.

Determination of the thickness of hair of various categories was carried out using an electron microscope and a computer application. The hairs were placed on a glass slide and under an average microscope magnification $(7 \mathrm{x} 40)$ using an eyepiece micrometre, then photographs were taken using a Panasonic DMC-FS42 camera and their diameter was analysed in the ImageJ computer program. Hair length was measured using a binocular electron microscope.

The softness of the hairline was calculated using the softness coefficient, defined as the ratio of the hair thickness at the widest point to its length.

The hair density was measured by the method of direct counting of the number of hairs in one bundle, previously removed from the sacrum area.

Hair strength was determined with a DSH-3M-2 dynamometer with a maximum load of $3 \mathrm{cH}$. The breaking load was determined by breaking 25 hair bundles with a length of 25 $\mathrm{mm}$ and an average weight of $4 \mathrm{mg}$. With tweezers, the hair bundles were taken from the plate and clamped (up to half of its length) in the upper clamp removed from the device. Then the clamp was put in place. The other end of the bundle was clamped in the lower clamp so that all hair in the clamped bundle were equally taut. The breaking load was determined on the scale of the device. After breaking all the bundles, the fibers were carefully collected with tweezers in a weighing bottle and weighed on an analytical balance with an error of no more than $\pm 0.1 \mathrm{mg}$.

Chinchilla fur gnawing areas were recorded using a Panasonic DMC-FS42 camera at the end of each decade (10 days) for 9 decades (90 days), as a result of electronic photographic recording, colour "jpg" files were obtained. The results were digitized using the ImageJ program with the determination of the area and degree of the damaged area of the hairline for each animal.

The damaged fur areas were divided into 4 groups:

0 degree - gnawing of fur $0 \%$ (no damage to the hairline);

1 degree - gnawing fur from $1 \%-20 \%$ (moderate damage to the hairline);

2 degree - gnawing fur $21 \%-40 \%$ (extensive damage to the hairline);

3 degree - gnawing fur $41 \%-60 \%$ (damage to the hairline is large).

Further, the fur damage coefficient (CFM) in the group was calculated using the formula: $\mathrm{CFM}=[0$ degree $* \mathrm{~N} 0+1$ degree $* \mathrm{~N} 1+2$ degree $* \mathrm{~N} 2+3$ degree $* \mathrm{~N} 3] / \mathrm{n}$, 
where N0, N1, N2, N3 is the number of objects with a degree of $0,1,2$ and 3 points, respectively, $\mathrm{n}$ is the number of objects.

The digital material was processed by the method of variation statistics using the MsExcel program. To identify statistically significant differences, the Student-Fisher test was used.

\section{Results and discussion}

When examining the hairline, it was found that the guide hairs (Fig. 1) in males in the control group are 5\% thicker than in males in the experimental group. In females of the control group, the diameter of the guide hairs was $20 \%$ larger than in females of the experimental group (Table 1). On average for the group, the difference was $13 \%$. The length of the guide hairs in males and females of both groups, on average, was approximately the same (Table 1).
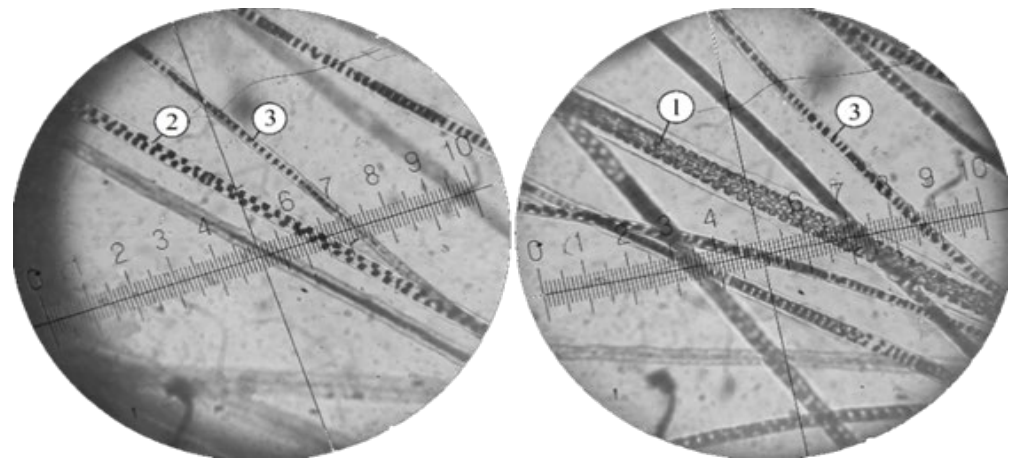

Fig. 1. Hair categories of Chinchilla lanigera: 1- guiding hair; 2 - guard hair; 3 - downy hair.

The guard hairs (Fig. 1) in males of both groups practically did not differ in thickness. In females of the control group, the diameter of the guard hairs exceeded that of females in the experimental group by $6 \%$. On average, in the experimental group, the thickness of the guard hair was less by $4 \%(\mathrm{p}<0.05)$ than in the control group (Table 1$)$. The length of the guard hairs in males of both groups was $28 \mathrm{~mm}$, and in females of the control group it was $3 \%$ longer. On average, there were no significant differences in hair length among the groups.

Table 1. Morphohistological indicators of the hairline of Chinchilla lanigera in the sacrum region.

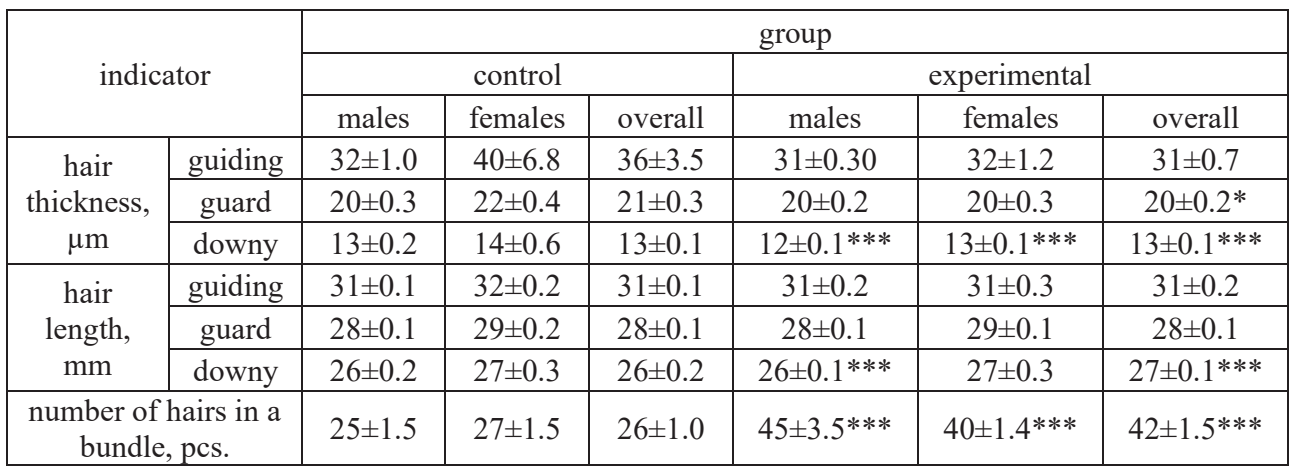

Note: here and below * - the difference between the control and experimental group with a reliability of $*$ - $\mathrm{p}<0.05 ; * *-\mathrm{p}<0.01 ; * * *-\mathrm{p}<0.001$. 
In the category of down hair (Fig. 1) in males and females of the experimental group, it was found that their thickness was $6 \%$ less $(\mathrm{p}<0.001)$ than in animals of the control group. The length of down hair in males in the experimental group is $3 \%$ longer than in the control $(p<0.001)$ (Table 1). In females of the experimental group, the length of downy hair was $2 \%$ more than in the control group. On average, in males and females of the experimental group, the length of down hair was $3 \%$ more $(p<0.001)$ than in the control group.

When examining the hair in the bundle, it was revealed that the number of hairs in males of the experimental group was $43 \%$ more than in the control group, in females of the experimental group - by $33 \%(\mathrm{p}<0.001)$ more. On average for the group, the difference was $38 \%(\mathrm{p}<0.001)$ (Table 1).

The coefficient of hair softness in males in the experimental group was 0.46 , which is $4 \%$ less $(p<0.01)$ than in males in the control group (Table 2$)$. In females of the experimental group, the softness coefficient was $0.45(\mathrm{p}<0.001)$, which is $10 \%$ less than in the control group (Table 2). Thus, the data obtained indicate a greater silkiness of the fur of the animals of the experimental group by an average of $6 \%(p<0.001)$ in comparison with the control group.

Table 2. Technological indicators of hair of Chinchilla lanigera in the region of the sacrum.

\begin{tabular}{|c|c|c|c|c|c|c|}
\hline \multirow{2}{*}{ indicator } & \multicolumn{5}{|c|}{ group } \\
\cline { 2 - 7 } & \multicolumn{3}{|c|}{ control } & \multicolumn{3}{|c|}{ experimental } \\
\cline { 2 - 7 } & males & females & overall & males & females & overall \\
\hline $\begin{array}{c}\text { hair } \\
\text { softness } \\
\text { coefficient, } \\
\text { C*10-3 }\end{array}$ & $0.48 \pm 0.006$ & $0.50 \pm 0.008$ & $0.49 \pm 0.005$ & $0.46 \pm 0.006^{* *}$ & $0.45 \pm 0.005^{* * *}$ & $0.46 \pm 0.004^{* * *}$ \\
\hline $\begin{array}{c}\text { hair } \\
\text { strength } \\
\text { coefficient, } \\
\text { cH/tex }\end{array}$ & $6.3 \pm 0.20$ & $7.2 \pm 0.18$ & $6.8 \pm 0.20$ & $7.4 \pm 0.29^{*}$ & $7.8 \pm 0.16^{*}$ & $7.6 \pm 0.18^{* *}$ \\
\hline $\begin{array}{c}\text { fur chewing } \\
\text { coefficient }\end{array}$ & $1.2 \pm 0.50$ & $4.5 \pm 1.02$ & $2.8 \pm 0.68$ & $0.3 \pm 0.18$ & $0.3 \pm 0.24^{* *}$ & $0.3 \pm 0.15^{* * *}$ \\
\hline
\end{tabular}

According to the coefficient of hair strength of animals, it was found that in males in the experimental group this indicator was $7.4(\mathrm{p}<0.05)$, which is $15 \%$ more than in the control (Table 2). In females of the experimental group, the coefficient of hair strength was 7.8 $(\mathrm{p}<0.05)$, which is $8 \%$ more than in the control group (Table 2$)$. This fact testifies to the greater strength of the hair of the animals of the experimental group by an average of $11 \%$ $(\mathrm{P}<0.01)$ in comparison with the control group.

As a result of observing the condition of the fur of chinchillas for 90 days, it was found that in the first decade, gnawing of fur was not observed in both groups.

In the second decade, $20 \%$ of males in the control group showed first-degree gnawing of fur (Figs. 1, 2), and in $60 \%$ of females of the control group - in $67 \%$ of cases of the first and $33 \%$ of the second degree (Fig. 4). Fur gouging was not observed in the experimental group.

In the third decade, $20 \%$ of males in the control group showed gnawing of fur of the second degree, in $80 \%$ of females of the control group - in $50 \%$ of cases of the first, $25 \%$ of the second and $25 \%$ of the third degree. Fur gouging was not observed in the experimental group.

In the fourth decade, $20 \%$ of males in the control group were observed gnawing fur of the second degree, and in $60 \%$ of females of the control group - in $33 \%$ of cases of the first and $67 \%$ of the second degree. In the experimental group, fur chewing did not appear. 
In the fifth decade, $20 \%$ of males in the control group showed first-degree gnawing of fur, in $80 \%$ of females in the control group - in $50 \%$ of cases of the first, $25 \%$ of the second and $25 \%$ of the third degree. Fur chewing was not observed in the experimental group.

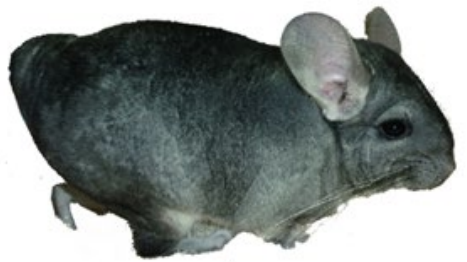

A

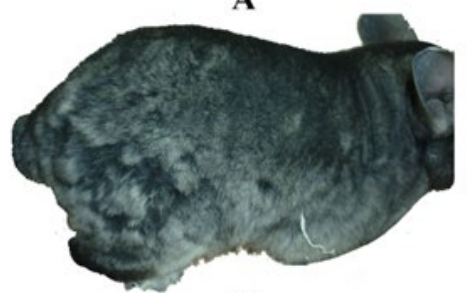

C

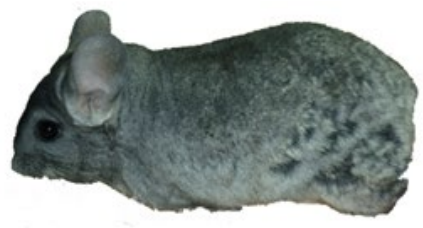

B

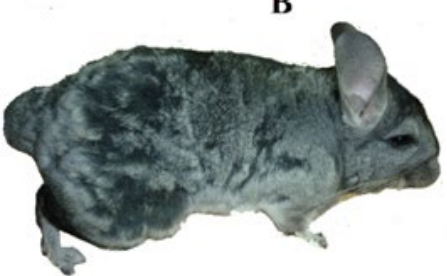

D

Fig. 2 The degree of the damaged hairline of Chinchilla lanigera: A - 0 degree; B - 1 degree; C - 2 degree; D - 3 degree.

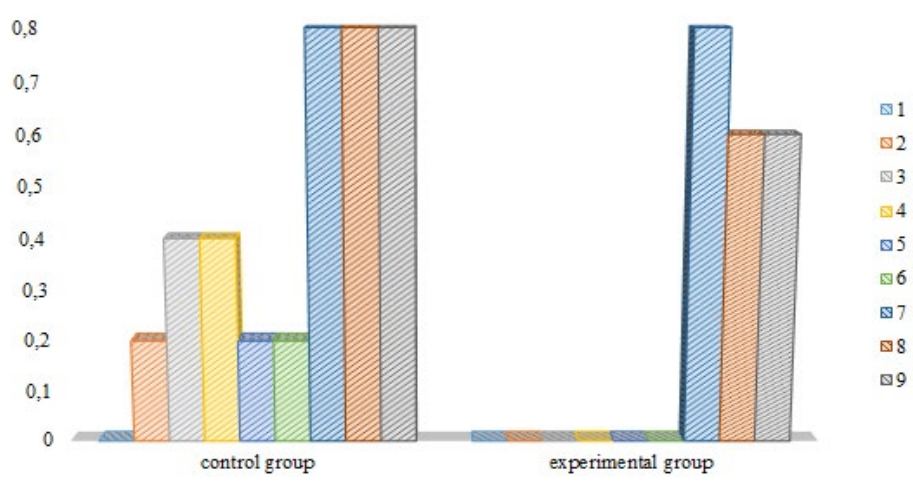

Fig. 3 Dynamics of gnawing of fur in males of Chinchilla lanigera. 1-9 - periods of raising animals.

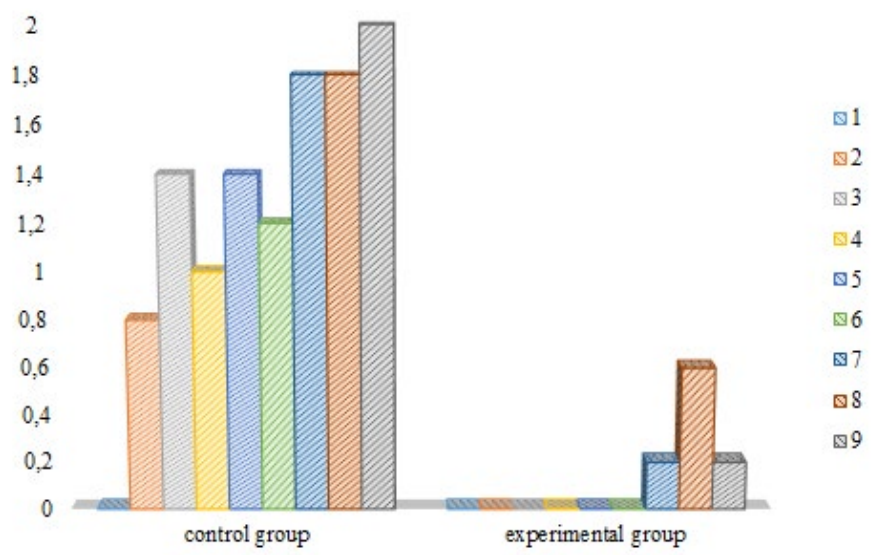

Fig. 4 Dynamics of gnawing of fur in females of Chinchilla lanigera. 1-9 - periods of raising animals. 
In the sixth decade, $20 \%$ of males in the control group had first-degree gnawing of fur, and in $80 \%$ of females of the control group - in $50 \%$ of cases of the first and $50 \%$ of the second degree. There was no fur gnawing in the experimental group.

In the seventh decade, $40 \%$ of males in the control group showed fur gnawing in $50 \%$ of cases of the first and $50 \%$ of the third degree, in $100 \%$ of females of the control group - in $40 \%$ of cases of the first, $40 \%$ of the second and $20 \%$ of the third degree. In the experimental group, $40 \%$ of the males showed fur gnawing in $50 \%$ of the first and $50 \%$ of the third degree, and in $20 \%$ of the females in the experimental group of the first degree.

In the eighth decade, fur gnawing was observed in $40 \%$ of males in the control group in $50 \%$ of cases of the first and $50 \%$ of the third degree, in $80 \%$ of females in the control group - in $75 \%$ of cases of the second and $25 \%$ of the third degree. In the experimental group, $20 \%$ of males showed third-degree gnawing of fur, and $40 \%$ of females in the experimental group - in 50\% of cases of the first and 50\% of the second degree.

In the ninth decade, fur gnawing was manifested in $40 \%$ of males in the control group in $50 \%$ of cases of the first and $50 \%$ of the third degree, in $100 \%$ of females in the control group $-40 \%$ of the first, $20 \%$ of the second and $40 \%$ of the third degree. In the experimental group, $20 \%$ of males showed third-degree gnawing of fur, and $20 \%$ of females in the experimental group of the first degree.

When calculating the coefficient of gnawing fur, it was found that in males and females of the experimental group, this indicator was $75 \%$ less than in males in the control group, and $93 \%(p<0.01)$ less than in females in the control group. The obtained data on the coefficient of fur gnawing show that the animals of the experimental group showed less tendency to gnaw fur on average by $89 \%(p<0.001)$ than the chinchillas of the control group (Table 2).

Insignificant differences were revealed in the chemical composition of the hairline in both groups. In the control group, the dry matter ratio was $93 \%$, and the moisture content was $7 \%$ (Fig. 5). In the experimental group, the dry matter indicator was lower, and the moisture content was $1 \%$ higher than in the control group. In terms of gender, the differences were identical. When analysing dry matter, it was found that in the experimental group there are less organic substances and more mineral substances by $1 \%(\mathrm{p}<0.05)$ than in the control group.

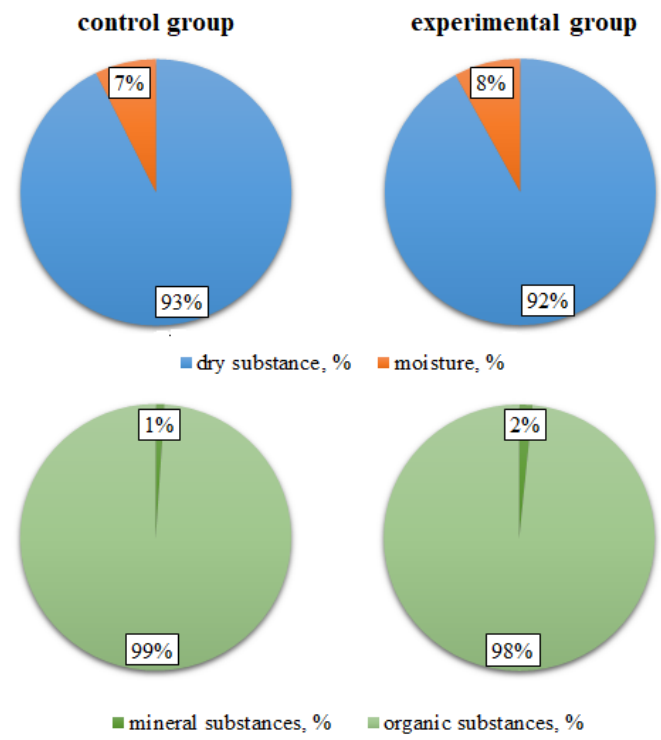

Fig. 5 Chemical parameters of hair of Chinchilla lanigera in the region of the sacrum. 


\section{Conclusion}

As a result of an experimental study, we found that the inclusion of water enriched with molecular hydrogen in the diet of a long-tailed chinchilla has a beneficial effect on the condition of the hairline. According to the area of the damaged area of fur (as a result of biting off the fur), it was found that in males of the experimental group, the coefficient of gnawing fur was $75 \%$ less than that of males in the control group, and in females of the experimental group - by $93 \%(p<0.01)$ less than in females of the control group. On average, the animals of the experimental group showed a lesser tendency to gnaw out fur by $89 \%(\mathrm{p}<0.001)$ than in the control group.

There was also a difference in hair thickness: on average, in the experimental group, the guard hairs were thinner by $4 \%(\mathrm{p}<0.05)$, compared with the control group, down hair in the experimental group was thinner by $6 \%(\mathrm{p}<0.001)$ than in animals of the control group. On average, the length of down hair in the experimental group was $3 \%$ higher $(p<0.001)$ than in the control group.

When studying the number of hairs in the bundle, it was found that males in the experimental group had $43 \%$ more hairs than in the control group, females in the experimental group had more hairs by $33 \%(\mathrm{p}<0.001)$. On average, in the experimental group, the indicator was $38 \%$ higher $(\mathrm{p}<0.001)$.

When calculating the coefficient of fur softness, it was found that in males of the experimental group the indicator is $4 \%(\mathrm{p}<0.01)$ less than in males in the control group, and in females of the experimental group it is $10 \%(\mathrm{p}<0.001)$ less than in females. control group. Thus, the data obtained indicate a greater silkiness of the fur of the animals of the experimental group by $6 \%(\mathrm{p}<0.001)$ in comparison with the control group.

When analyzing the strength of the hair of animals, it was found that in males in the experimental group, the strength coefficient was $15 \%(\mathrm{p}<0.05)$ higher than in the control group, and in females in the experimental group - by $8 \%(\mathrm{p}<0.05)$ more than in the control group. On average, in the experimental group, the hair strength was $11 \%$ higher $(\mathrm{p}<0.01)$ compared to the control group.

When considering the data on the chemical composition, it was found that in the dry matter of the experimental group there are less organic substances and more mineral substances by $1 \%(\mathrm{p}<0.05)$, compared with the control group.

\section{References}

1. P. Valladares, M. Espinosa, M. Torres, E. Diaz, N. Zeller, J. de La Riva, M. Grimberg, A. Spotorno, Mastozool. Neotrop. 19, 173-178 (2012)

2. M. Novikov. Veterinary medicine. Zootechnics and Biology 2, 23-32 (2015)

3. R. Głogowski, D. Dzierżanowska-Góryń, K. Rak. SGGW. Anim. Sci. 52, 23-28 (2013)

4. J. Lanszki. Scientifur 23, 267-270 (1999)

5. Ö. Poyraz, Z. Akinci, E. Onbaşilar, J. Vet. Anim. Sci 29, 381-384 (2005)

6. P. Wolf, A. Schröder, A. Wenger, J. Kamphues. J. Anim. Physiol. Anim. Nutr 87, 129133 (2003)

7. Y. Gladilov. Rabbit breeding and fur farming 1, 20 (2015)

8. E. Koldaeva. Rabbit breeding and fur farming 2,14-15 (2015)

9. M. Novikov, M., 156 (2010)

10. V. Grishin, M. Moiseev, RUDN 4, 58-59 (2008) 
11. M. Novikov, T. Reusova, N. Balakirev. Veterinary, Animal Science and Biotechnology 2, 55-64 (2021)

12. N. Pavlova M., (1971)

13. A. Gromova, G. Nozdrin. NSAU, 1, 91-99 (2016)

14. V. Franchi Parra, O. Aleuy, T. Tadich Gallo Journal of Veterinary Behavior, 11 60-64 (2016)

15. M. Ponzioa, S. Monfort, J. Busso, V. Carlini, R. Ruiz, M. Cuneo. Hormones and Behavior 61(5), 758-762 (2012)

16. M. Tisljar, D. Janic, Z. Grabarevic, A. Marinculic, L. Pinter, Z. Janicki, A. Nemanic. Acta. Vet. Hung. 50, 133-142 (2002)

17. S. Lapinski, M. Lis, A. Wójcik, L. Migdal, I. Guja. Ann. Anim. 14, 189-195 (2014)

18. T. Tadich, V. Franchi, D. Navarrete. Avances en Ciencias Veterinarias 28, 41-48 (2013)

19. L. Terskaya, 143 (M.: Yurayt, 2018)

20. G. Chupakhina, N. Chupakhina, P. Maslennikov, 191 (IKBFU Publishing House. I. Kant, 2019)

21. I. Bondarenko, O. Lysenko, Primorsky State Agricultural Academy, (2019)

22. B. Tikhonov, A. Sidorov, M. Sulman. Tver State Technical University, 1 (43), 23-29 (2021)

23. B. Mehrinigori, M. Ikromi, K. Mirzorakhimov, PAYOMI DTT, 4 (43) (2020)

24. K. Melkonyan, T. Rusinova, Y. Kozmay, V. Nikonenko, N. Pismenskaya, A. Kozmay. KubGMU, (2021)

25. L. Fan, H. Chen, J. Liang, Da Chen \& Y. Huang. Applied Nanoscience, 11, 833-840 (2021)

26. L. Yang, D. Li, S. Chen. Open Med, 11(1), 399-406 (2016)

27. N. Jafta, S. Magagula, K. Lebelo, D. Nkokha, M. Mochane. Applied Water Science, 1 (2021)

28. J. Hancock, T. LeBaron, G. Russell. Reactive Oxygen Species, 11 (2021)

29. T. Ishibashi. Curr Pharm Des, 19 (35), 6375-638 (2013)

30. J. Fu, et al. Molecular Medicine Reports. 18(6), 5009-5015 (2018)

31. S. Ohta Biochim. Biophys. Acta Gen. Subj, 1820(5), 586-594 (2012)

32. H. Ono, Y. Nishijima, N. Adachi, M. Sakamoto, Y. Kudo, K. Kaneko, A. Nakao, T. Imaoka. Med. Gas Res., 21 (2012)

33. J. Cui. Neuroscience, 335, 232-241 (2016)

34. S. Ohta. Pharmacol. Ther., 144, 1-11 (2014)

35. B. Kura, A. Bagchi, P. Singal, M. Barancik, T. LeBaron, K. Valachova, L. Šoltés, J. Slezák Can. J. Physiol. Pharmacol, 97(4), 287-292 (2019)

36. M. Henry, J. Chambron. Water, 5(4), 2094-115 (2013)

37. M. Ichihara, S. Sobue, M. Ito, M. Ito, M. Hirayama, K. Ohno. Med. Gas Res., 5, 1-21 (2015)

38. M. Dole, F. Wilson W. Fife. Science, 190, 152-154 (1975)

39. I. Ohsawa. Nature medicine, 13, 688-694 (2007)

40. C. Zhang, Y. Tang, X. Xu, S. Guo H. Wang. Experimental and therapeutic medicine, 9, 2114-2120 (2015) 
41. A. Shao, et al. Molecular neurobiology 53, 3462-3476 (2015)

42. C. Wang, et al. Neuroscience letters 491, 127-132 (2011)

43. K. Nagata, N. Nakashima-Kamimura, T. Mikami, I. Ohsawa, S. Ohta. Neuropsychopharmacology: ofcial publication of the American College of Neuropsychopharmacology 34, 501-508 (2009)

44. E. Panina, A. Ivanov, D. Petrov, S. Panteleev. E3S Web of Conferences 254, 08008 (2021)

45. Y. Suzuki, M. Sano, K. Hayashida, I. Ohsawa, S. Ohta, K. Fukuda. FEBS Lett. 583 (13), 2157-2159 (2009)

46. T. Sato, S. Mimuro, T. Katoh, T. Kurita, S. Truong, K. Kobayashi, H. Makino, M. Doi, Y. Nakajima J. Anesth., 1-8 (2020)

47. H. Oharazawa, T. Igarashi, T. Yokota, H. Fujii, H. Suzuki, M. Machide, H. Takahashi, S. Ohta, I. Ohsawa. Vis. Sci 51, 487-492 (2010)

48. K. Hayashida, M. Sano, I. Ohsawa, K. Shinmura, K. Tamaki, K. Kimura, J. Endo, T. Katayama, A. Kawamura, S. Kohsaka. Biochem. Biophys. Res. Commun 373, 30-35 (2008)

49. Y. Zhang, J. Xu, Z. Long, C. Wang, L. Wang, P. Sun, P. Li, T. Wang. Front. Pharmacol 7, 1-12 (2016)

50. J. Cardinal, J. Zhan, Y. Wang, R. Sugimoto, A. Tsung, K. McCurry, T. Billiar, A. Nakao. Kidney Int 77, 101-109 (2010)

51. T. LeBaron, A. Larson, S. Ohta, T. Mikami, J. Barlow, J. Bulloch, M. DeBeliso. J. Lifestyle Med 9(1), 36-43 (2019)

52. M. Ito, M. Hirayama, K. Yamai, S. Goto, M. Ito, M. Ichihara, K. Ohno. Med. Gas Res, 15 (2012)

53. M. Ichihara, S. Sobue, M. Ito, M. Ito, M. Hirayama, K. Ohno. Med. Gas Res, 5, 1-21 (2015)

54. M. Hirayama, M. Ito, T. Minato, A. Yoritaka, T. LeBaron, K. Ohno. Med. Gas Res, 8(4), 144-149 (2018)

55. A. Tamasawa, K. Mochizuki, N. Hariya, M. Saito, H. Ishida, S. Doguchi, S. Yanagiya, T. Osonoi. J. Pharmacol 762, 96-101 (2015)

56. L. Qian, J. Shen, Y. Chuai et al. J. Biol Sci 9, 887-894 (2013)

57. M. Baeeri, S. Mohammadi-Nejad, M. Rahimifard et al. Mol Cell Biochem 441, 21-33 (2018)

58. P. Zhou, B. Lin, P. Wang et al. J. Radiat Res 60, 17-22 (2019)

59. L. Hong, Y. Yaru, L. Jing, L. Binghui, W. Huimin, Y. Luxun, W. Weidong, L. Rong. J. Radiat Res 62(1), 34-45 (2021) 